\title{
Face-to-face is the most effective media for communication over social media
}

\author{
Svenja Arabella Hallerberg, Madawala Liyanage Duminda Jayaranjan, \& Sumaia Farzana \\ Siam University, Bangkok, Thailand
}

\begin{abstract}
Global teams need to know how to be successful in effective communication. Global leaders or international students should be able to manage diverse international teams. The paper reveals information into some communication theories and discusses their today's applicability. Technological advancement such as social media can create new opportunities to communicate virtually with dispersed teams in one country or globally. Since there is not much known about the effectiveness of using social media, the research paper focused on the challenges to communicate with social media channels. The study revealed that the main reason for using social media is because of the convenience and easiness. When having the choice to choose one communication channel, face-to-face communication is still seen as the most effective form to communicate. Yet social media channels can contribute to build a strong network.
\end{abstract}

Keywords: effective communication, intercultural communication, choice of media

\section{INTRODUCTION}

The current trend on globalization and digitalization leads to an increasing need for effective communication and collaboration. Hence, teams can be dispersed globally and therefore, global companies need to know how to develop an effective communication method and manage a diverse international team. Technological advancement creates opportunities in supporting virtual communication. Global human exchanges are accompanied by technologies that affect synchronous and asynchronous communication and therefore can facilitate collaboration. In the past, agreements have been organized through face-toface meetings, whereas nowadays e-mails, video conferences, and social media foster virtual teamwork (Steers et al. 2010).

Communication can be described as an intentional activity, which requires willingness, a goal or a certain purpose (Ant et al. 2013). Organizational communication is the discipline which deals with the study of communication processes within the organizational field (Durneac 2012). The discipline needs to be understood to manage communication of global teams. Due to the introduction of new forms of electronic communication media, global leaders can benefit from the facilitation of organizational communication. Nevertheless, technical feasibility does not necessarily mean that the quality of communication improves (Suh 1999). The use of media, especially the distinction between the different types of communication, from virtually to face-to-face.

The first model was developed in 1949 (Shannon \& Weaver 1998, Ant et al. 2013). The model states, there is a transmitter converting the message into a signal to send it over to the communication channel of the receiver. During the process of transmission, there are unwanted and intended additions, which are called noises (distortions of sound, distortions of shape or shading of a picture or errors in transmission). These noises can change the transmitted signal. The communication system by Shannon \& Weaver (1998) is symbolized as shown in figure 1. Watzlawick et al. (1996) stated that communication is not only done via words, but also nonverbal channels like facial expressions, gesture, and body posture (Watzlawick et al. 1996). This goes in line with the research of Thun (2014), who discovered that communication is always multidimensional (Rollka \& Schultz 2011). The communication square 
(or also known as the four-ear model) by Thun (2014) shows that a statement has four different effects and includes four messages simultaneously (factual information, a self-statement, a relationship indicator, and an appeal). These communication theories have something in common: the models reveal that physical social presence is important to deliver the context via all sensors channels to ensure effective communication. Furthermore, every message can be analyzed from a content and relation perspective. It focuses on the aspect of how communication works, but not on which medium is the best to support effective communication.

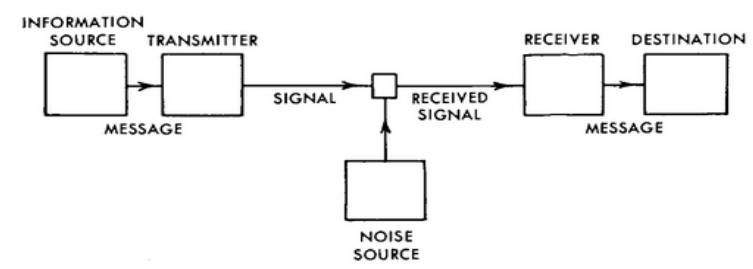

Figure 1: Communication system by Shannon \& Weaver (Shan-non \& Weaver, 1998)

There is little known about how people make their choice about media in order to communicate effectively. A current gap in research results from the rapid transformation of social media. Therefore, this paper elaborates the research question, where the social media stands for communication and networking in teams? The aspects linked to this specific question will be analyzed based on the literature and an online survey.

\section{RESEARCH METHODS}

The communicational theories such as Social Presence Theory (SPT), Media Richness Theory (MRT) and Media Synchronicity Theory (MST) can explain which factors might lead to effective communication. In order to find out which factors lead to a good understanding among global teams, a survey was taken to identify which aspects are important when communicating effectively in global teams. The information gained by literature research was used to design the Internet-based Survey. The open access survey website Survey Monkey was used to design the survey. The sample for this survey consists of voluntarily participants. The questionnaires were revised according to the experiences from a pre-test before publishing the questionnaire. Survey monkey allows you to share the draft with other people. At this stage questions were identified, that needs to be clarified with more answer options. Also question types were added to make sure that there are no possible misunderstandings for participants. The data was collected through a questionnaire with twenty questions. The first part of the questionnaire contained mainly demographic questions. The second part asked questions about the use of communication media, but also how to build a network. Figure 2 illustrates the overall conceptual methodology.

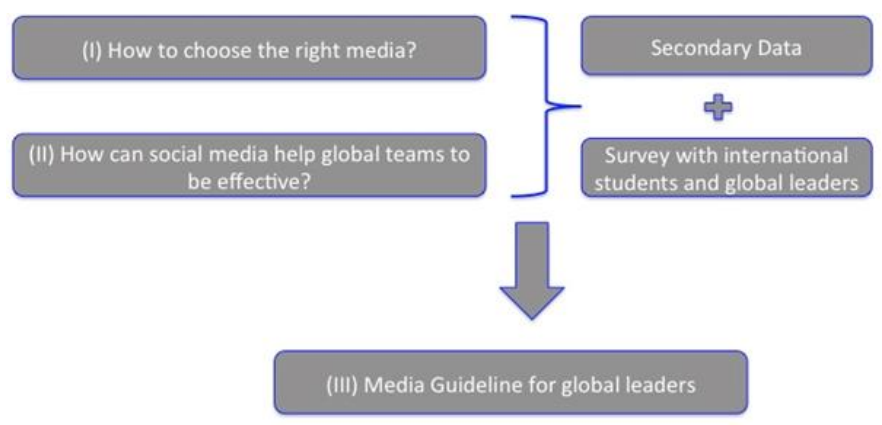

Figure 2: Conceptual Methodology Framework

\section{RESULTS AND DISCUSSIONS}

The Most effective way of communication: When communicating with people from other countries most participants agree that face-to-face communication is the most efficient way to communicate with people from a different cultural background. The opinion of video conferencing tools, such as Skype or normal phone calls cannot be identified. "Line" application is seen as an ineffective way to communicate with people from other countries. This can be explained by the fact that Germans normally do not use Line. Surprisingly the Facebook-messenger is also not seen as an effective way to communicate with people from other countries.

Table 1: Use of communication tools

\begin{tabular}{cccccc}
\hline \multirow{2}{*}{$\begin{array}{c}\text { Communication } \\
\text { Tool }\end{array}$} & 1 & 2 & 3 & 4 & 5 \\
\cline { 2 - 6 } & 7.69 & 15.38 & 17.95 & 5.13 & 53.8 \\
Line & 10.53 & 50.00 & 13.16 & 15.79 & 10.53 \\
Whats App & 2.56 & 10.26 & 17.95 & 30.77 & 38.46 \\
Facebook Messenger & 12.50 & 60.00 & 17.50 & 5.00 & 5.00 \\
E-Mail & 5.26 & 18.42 & 10.53 & 18.42 & 47.37 \\
Skype/Internet call & 7.69 & 48.72 & 23.08 & 15.38 & 5.13 \\
Phone Call & 19.51 & 68.29 & 4.88 & 0.00 & 7.32 \\
Face-to-Face & & & & &
\end{tabular}


Effective Team Size: Most participants agree that effective communication is possible by a team size up to six people.

The reason for choosing specific media channel cannot be clearly defined since $48.48 \%$ chose their media depending on the situation and $39.39 \%$ depending on the complexity of information. The remaining $12.12 \%$ chose their media channel by following the majority. Therefore, it is not possible to argue, the majority of people would rather follow the MRT or MST. Having the choice to communicate face-to-face or virtually, $80 \%$ would only or mostly prefer to communicate face-to-face than virtually (Table 1 ).

Communication Barriers: The most appearing barrier when communicating with intercultural teams are language $(68.75 \%)$ and cultural barriers $(25.00 \%)$. Therefore, the first priority for global leaders would be to provide language training and followed by cross-cultural training.

How to choose the right media: Regarding building networks, $54.84 \%$ of the participants agreed on building their network face-to-face. But, there are also people who preferred to use social media channels (19.35\%), networking websites (16.13\%), and business events $(9.68 \%)$. While none preferred social events.

Effective communication: It is dependent on how both communication partners agree on the communication channel. This is why global leaders need to ensure that everyone is familiar with the communication channel. In order to guarantee effective communication, you always have to listen carefully and actively to your communication partner/team/employee and assure that there are no misunderstandings. Especially, when it comes to distance leadership global leaders have to make sure that there is a shared understanding of goals to reach and time schedules for each milestone. Also, building trust and an honest atmosphere among the team will increase effective communication and strengthen your network. When working in intercultural teams, cultural differences need to be understood, which is possible through cultural trainings. In general, media theories can be clustered in five ways of how to choose media. Global leaders can make a rational choice when using fact-based arguments. All characteristics are seen in an impartial way. When making a social choice, leaders have to take social settings into account, like normative expectations and behavioral patterns. Personal experiences and social constraints influence the decision-making person. Further actions can be conducted by symbolic behavior. The constructions of meanings are individual and therefore behavior is interpreted in different ways. On the one hand, interpersonal choice of media is present when individuals adjust their choice of media to the specific communication situation and partner regarding their media preferences. Technology acceptance is influenced by the attitude towards media use, which is depending on the perceived usefulness and ease of use. All these aspects are also depending on prior experience, subjective attribution, biographical background, and attitude of the social group (Misoch 2006).

Trevino et al. (1987) revealed that three main reasons influenced manager's choice of media: ambiguity of the message content and richness of the communication medium, symbolic cues provided by the medium, and situational determinants such as time and distance. Another finding of the study is that face-to-face communication was mainly selected for content and symbolic reasons, while communication via telephone or electronic mail was chosen due to situational constraints. These explanations showed that the choice of media could be made in several ways. The survey showed that most people do make their choice depending on every situation and how complex the information that needs to be delivered.

How can social media help global teams to be effective: The results of the survey showed that social media is mainly used for leisure activities. The paper revealed several advantages of social media for communication. Nevertheless, face-to-face communication is still preferred for communication with other team members from the same and other countries. The survey and the literature review show that social media is seen as a reasonable channel to build a network and strengthen effective communication. However, it is still not possible to be effective in communication when using electronic channels only. Global teams need to find a way to use the benefits of social media.

Guidelines for communication: Reflecting on the survey and the literature review, concrete recommendations for actions can be derived from the survey results. Global leaders have to identify the medium, which changes understanding within a time interval. In contrast to the SPT and MRT, it is important to not only focus on the task itself but also on the processes and the people involved. Taking the Shannon-Weaver-Model into account, it has to be ensured that the receiver understands the message that the sender planned to send (Shannon \& Weaver 1998). As Watzlawick et al. (1996) noticed communication consists of many signals. These 
communication signals might get lost through technology-mediated communication. Low media quality can lead to a loss of gesture and facial expressions (Storck \& Sproull, 1995). Besides ensuring effective communication, leaders also focus on the financial outcome of the company. Therefore decisions are taken rationally. Furthermore, the effects of verbal and nonverbal components of a message are relevant when it comes to building a strong network and to deliver information beyond the written words. Missing out the nonverbal symbols can have significant effects on social perceptions. Managing a big group of people requires managers to think of media that allows parallelism. Leaders also have to consider reprocessability and rehearsability, especially when it comes to sensitive data.

Working successfully in a global team requires conveyance and convergence processes. Therefore, global leaders should introduce a variety of media instead of just one medium, thus communication performance can be improved (Dennis et al. 2008). For global teams, the same symbolic understanding is relevant (Cox \& Blake 1991).

The Intranet allows companies to publish information (e.g. latest news, internal regulations, job offers, and etc. among their employees (Durneac 2012). Video conference tools such as Skype not only allow to call colleagues via video conference but also allow instant messaging and working on the same document simultaneously. There are also numerous other tools such as Every TimeZone, SpaceTime.am, Timezone.io to keep track of what time it is at the colleague's place. These tools are quite helpful for teams within different time zones and especially enable the team to know when to schedule meetings for video conferences (Laurinavicius 2016).

To ensure that employees take advantages of the mentioned media tools, global leaders should secure that every team member is capable to use the tools effectively. Frequent dialog-orientated communication enables global leaders to spot gaps in their employee's media knowledge and communication skills in order to identify opportunities for training (Buckingham \& Goodall 2015). Thus, the organization has to implement a media guideline. Media guidelines can be used throughout the organization to reduce conflicts in choosing the right medium for a specific situation. Furthermore, data security is a critical topic in today's internet communication. Data that is either highly sensitive to the company or consists of personal data, should only be accessible by advised and authorized persons. Especially, when it comes to the usage of social media, there should be a specific group of administrator rights (Kaplan \& Haenlein 2010).

\section{CONCLUSIONS}

This paper showed that every company, which is able to connect across borders and maintain an effective communication in a diverse team can strengthen team cohesion, employee engagement and improve the overall workforce productivity. Not only these research gaps have to be addressed in the future, but organizations must be aware of the risks and challenges of communication in global teams every day. The organizations should put their efforts into providing training and development for the employees and global leaders.

There is a constant development of new technologies and new forms of media. Therefore, future research needs to be done with regard to all aspects of communication with new media. Furthermore, the research has to be continued and more interesting outputs or theories can be introduced to leaders who wish to identify best suitable tools for specific uses. Further research may also focus on effective integration between direct communication means and various social media platforms and artificial conversation like chatbot, and talk-bot, and etc.

\section{REFERENCES}

Ant, M., Nimmerfroh, M. C., \& Reinhard, C. 2013. Effiziente Kommunikation: Theorie und Praxis am Beispiel Die 12 Geschworenen. Heidelberg: Springer.

Buckingham, M. \& Goodall, A. 2015. Reinventing Performance Management. Harvard Business Review 4: 4050.

Cox, T.H. \& Blake, S. 1991. Managing cultural diversity: Implications for organizational competitiveness. The Executive 5(3): 45-56.

Dennis, A.R., Fuller, R.M. \& Valacich, J.S. 2008. Media, tasks, and communication processes: A theory of media synchronicity. MIS Quarterly 32(3): 575-600.

Durneac, C.P. 2012. The impact of information technologies upon the organizational communication. Acta Universitatis Danubius. Communicatio 6(1) : 102-113.

Kaplan, A.M. \& Haenlein, M. 2010. Users of the world, unite! The challenges and opportunities of Social Media. Business horizons 53(1): 59-68.

Laurinavicius, T. 2016. 20 Of The Best Time Tracking Tools To Increase Your Productivity. Forbes magazine. Retrieved from https://www.forbes.com/sites/ tomaslaurinavicius/2016/12/20/time-tracking-tools/. 
Misoch, S. 2006. Online-Kommunikation. UVK Verlag: Konstanz.

Rollka, B. \& Schultz, F. 2011. Kommunikationsinstrument Menschenbild: Zur Verwendung Von Menschenbildern in Gesellschaftlichen Diskursen. Wiesbaden: Springer..

Shannon, C.E. \& Weaver, W. 1998. The mathematical theory of communication. Champaign: University of Illinois press..

Steers, R.M., Sanchez-Runde, C.J. \& Nardon, L. 2010. Management across cultures: Challenges and strategies. Cambridge: Cambridge University Press.

Storck, J. \& Sproull, L.1995. Through a Glass Darkly What Do People Learn in Videoconferences? Human Communication Research 22(2):197-219.

Suh, K.S. 1999. Impact of communication medium on task performance and satisfaction: an examination of mediarichness theory. Information \& Management 35(5) : 295312.

Thun, S.V. 2014. Miteinander reden. Reinbek: RowohltTaschenbuch-Verlag

Trevino, L.K., Lengel, R.H. \& Daft, R.L. 1987. Media symbolism, media richness, and media choice in organizations: A symbolic interactionist perspective. Communication Research 14 (5): 553-574.

Watzlawick, P., Beavin, J.H. \& Jackson, D.D. 1996. Menschliche Kommunikation. Frankfurt: Fischer. 